\title{
Variation in extubation failure rates after neonatal congenital heart surgery across Pediatric Cardiac Critical Care Consortium hospitals
}

\author{
Brian D. Benneyworth, MD, MS, a,b Christopher W. Mastropietro, MD, ${ }^{a}$ Eric M. Graham, MD, \\ Darren Klugman, MD, ${ }^{\mathrm{d}}$ John M. Costello, MD, MPH, ${ }^{\mathrm{e}}$ Wenying Zhang, MS, ${ }^{\mathrm{f}}$ and \\ Michael Gaies, MD, MPH, $\mathrm{MS}^{\mathrm{f}}$
}

\begin{abstract}
Objective: In a multicenter cohort of neonates recovering from cardiac surgery, we sought to describe the epidemiology of extubation failure and its variability across centers, identify risk factors, and determine its impact on outcomes.

Methods: We analyzed prospectively collected clinical registry data on all neonates undergoing cardiac surgery in the Pediatric Cardiac Critical Care Consortium database from October 2013 to July 2015. Extubation failure was defined as reintubation less than 72 hours after the first planned extubation. Risk factors were identified using multivariable logistic regression with generalized estimating equations to account for within-center correlation.
\end{abstract}

Results: The cohort included 899 neonates from 14 Pediatric Cardiac Critical Care Consortium centers; $14 \%$ were premature, $20 \%$ had genetic abnormalities, $18 \%$ had major extracardiac anomalies, and $74 \%$ underwent surgery with cardiopulmonary bypass. Extubation failure occurred in 103 neonates $(11 \%)$, within 24 hours in $61 \%$. Unadjusted rates of extubation failure ranged from $5 \%$ to $22 \%$ across centers; this variability was unchanged after adjusting for procedural complexity and airway anomaly. After multivariable analysis, only airway anomaly was identified as an independent risk factor for extubation failure (odds ratio, $3.1 ; 95 \%$ confidence interval, $1.4-6.7 ; P=.01$ ). Neonates who failed extubation had a greater median postoperative length of stay (33 vs 23 days, $P<.001)$ and in-hospital mortality $(8 \%$ vs $2 \%, P=.002)$.

Conclusions: This multicenter study showed that $11 \%$ of neonates recovering from cardiac surgery fail initial postoperative extubation. Only congenital airway anomaly was independently associated with extubation failure. We observed a 4-fold variation in extubation failure rates across hospitals, suggesting a role for collaborative quality improvement to optimize outcomes. (J Thorac Cardiovasc Surg 2017;153:1519-26)

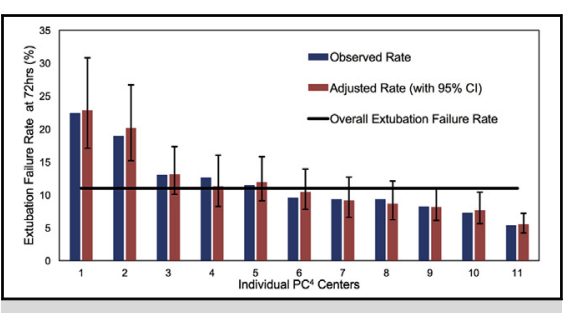

Observed and adjusted rates of extubation failure for neonates after cardiac surgery.

\section{Central Message}

Extubation failure occurs in $11 \%$ of neonates after cardiac surgery, with 4-fold variation across centers that may be modifiable.

\section{Perspective}

Extubation failure is common in neonates after cardiac surgery; considerable variation in these rates exists across centers. Airway anomaly was the only identified risk factor in this multicenter cohort, suggesting that center practices might underlie the observed variation. Collaboratives, including the Pediatric Cardiac Critical Care Consortium, are suited to identify best practices and improve outcomes.

See Editorial Commentary page 1527.
Pediatric cardiac critical care providers often are challenged with the equally important but often conflicting goals of minimizing patients' exposure to mechanical ventilation and preventing extubation failure. ${ }^{1-3}$ Although

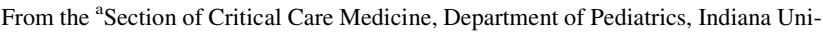
versity School of Medicine; ${ }^{\mathrm{b}}$ Children's Health Services Research, Department of Pediatrics, Indiana University School of Medicine, Indianapolis, Ind; 'Division of Cardiology, Department of Pediatrics, Medical University of South Carolina, Charleston, SC; ${ }^{\mathrm{d}}$ Division of Cardiac Critical Care Medicine and Cardiology, Children's National Health System, Washington, DC; ${ }^{\mathrm{e} D i v i s i o n}$ of Cardiology, Department of Pediatrics, Northwestern University Feinberg School of Medicine, Ann \& Robert H. Lurie Children's Hospital of Chicago, Chicago, Ill; and 'Division of Cardiology, Department of Pediatrics and Communicable Diseases, C.S. Mott Children's Hospital and University of Michigan Medical School, Ann Arbor, Mich.
}

early extubation protocols may improve outcomes for certain populations in pediatric cardiac intensive care units (ICUs), extubation failures have been associated with adverse outcomes, including increased duration of

Dr Gaies receives support from the National Heart, Lung, and Blood Institute (K08HL116639, Principal Investigator), which indirectly supports this research. Received for publication June 30, 2016; revisions received Dec 20, 2016; accepted for publication Dec 30, 2016; available ahead of print March 1, 2017

Address for reprints: Brian D. Benneyworth, MD, MS, 705 Riley Hospital Dr, Riley Phase 2, 4906, Indianapolis, IN 46202-5225 (E-mail: bbenneyw@iu.edu). $0022-5223 / \$ 36.00$

Copyright (C) 2017 by The American Association for Thoracic Surgery http://dx.doi.org/10.1016/j.jtcvs.2016.12.042 


\section{Abbreviations and Acronyms \\ GEE $=$ generalized estimating equation \\ ICU $=$ intensive care unit \\ IRB = institutional review board \\ LOS $=$ length of stay \\ $\mathrm{PC}^{4}=$ Pediatric Cardiac Critical Care Consortium}

Scanning this QR code will take you to a supplemental video for the article.

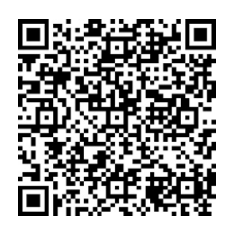

hospital stay, cardiac arrest, and mortality. ${ }^{4,5}$ Although these outcomes in part reflect overall illness severity and are not exclusively the result of extubation failure, patients may experience downstream complications of extubation failure, such as airway injury, prolonged mechanical ventilation, and the numerous consequences of prolonged exposure to critical care therapies. As such, collaborative efforts to reduce extubation failure events comprising all members of a congenital cardiac surgical program, including surgeons, anesthesiologists, intensivists, and cardiologists, can lead to great benefits for patients. A recent study conducted by the Pediatric Heart Network aimed at optimizing mechanical ventilation practices is a notable example of the importance of multidisciplinary collaboration when addressing issues related to surgery for congenital heart disease. $^{6}$

Reliable measures of extubation readiness, although validated in adult patients, remain elusive in pediatric and neonatal intensive care. Among pediatric patients of all ages in the cardiac ICU included in 2 multi-institutional registries, risk factors for extubation failure have included young age, genetic syndromes, surgical complexity, delayed sternal closure, postoperative infections or complications, and duration of mechanical ventilation. ${ }^{4,5}$ Neonates in the cardiac ICU consistently have demonstrated an increased risk of extubation failure relative to their pediatric counterparts; previous investigation focusing on these patients consistently report extubation failure rates from $17.5 \%$ to $22.0 \%$ of patients compared with overall rates of approximately $6 \%$ in all patients in the cardiac ICU. ${ }^{4,7}$ These studies also suggest worse clinical outcomes associated with extubation failure in neonates. ${ }^{7-9}$

To date, extubation failure after neonatal congenital heart surgery has been studied only in single-center populations or as part of the larger pediatric population. It is possible that the epidemiology and risk factors for extubation failure in neonates vary differently across hospitals. As such, studies exploring this life-threatening complication using large multicenter datasets are sorely needed to design interventions aimed at minimizing its occurrence. We sought to use the data available within the Pediatric Cardiac Critical Care Consortium $\left(\mathrm{PC}^{4}\right)$ registry to describe the epidemiology of extubation failure in neonates recovering from congenital heart surgery across multiple centers and identify risk factors for its occurrence.

\section{MATERIALS AND METHODS Data Infrastructure}

The $\mathrm{PC}^{4}$ is a quality improvement collaborative currently including hospitals from North America that participate voluntarily. ${ }^{10}$ The registry contains data on patients with primary cardiac disease admitted to an ICU under the care of a cardiac critical care attending. For this data analysis, data from 14 hospitals actively submitting cases between October 1, 2013, and July 31, 2015, were included. The registry collects patient demographics, cardiac ICU encounter characteristics, surgical data, critical care practices, and outcomes. For each episode of mechanical ventilation, the date and time of initiation, the date and time of extubation, and whether an extubation is planned or unplanned were recorded. $\mathrm{PC}^{4}$ data entry for surgical variables uses common data definitions and terminology and is integrated with the site's local data collection for the Society of Thoracic Surgery Congenital Heart Surgery Database as previously described. ${ }^{10}$

Trained data managers who pass an annual certification examination enter data into the registry. All data fields are defined according to standardized definitions. $\mathrm{PC}^{4}$ conducts weekly data-collection team teleconferences to review variable definitions and resolve questions related to data entry. Cases cannot be submitted to the registry unless all mandatory data fields are complete, and approximately $90 \%$ of fields are required for submission. There were no missing data in the study cohort on variables necessary for the analysis. The $\mathrm{PC}^{4}$ Data Coordinating Center audits every participating center on a regular schedule using a combined method of blind chart abstraction by auditors and source data verification including cardiac ICU census review. The results of auditing processes indicated an aggregate overall accuracy of $99.1 \%$, a major discrepancy rate of $0.62 \%$, and no evidence of selective case omission. ${ }^{11}$ Participation in $\mathrm{PC}^{4}$ is considered quality improvement by the local institutional review board (IRB) at each site that participated in this study, and as such, the local IRB waived the need for approval. The University of Michigan IRB provides oversight for the $\mathrm{PC}^{4}$ data coordinating center; this study was reviewed and approved with waiver of informed consent.

\section{Patient Population}

All neonates who underwent cardiac surgery at age 30 days or less, who had a cardiac ICU encounter between October 1, 2013, and July 31, 2015, and who had data submitted to the $\mathrm{PC}^{4}$ registry were included in the analysis. Only the neonate's index surgical encounter that resulted in postoperative mechanical ventilation was included. Neonates were excluded if they weighed less than $2.5 \mathrm{~kg}$ and were undergoing isolated closure of patent ductus arteriosus, were extubated before arrival to the cardiac ICU, had a tracheostomy before cardiac surgery, died before a planned extubation attempt, or were extubated with the intention of withdrawal of life-sustaining therapy.

\section{Data Variables and Outcomes}

Patient, preoperative, operative, and postoperative clinical variables were chosen a priori as potential risk factors for extubation failure. 
Weight-for-age $z$-score was calculated using World Health Organization or Centers for Disease Control standards according to patient age. ${ }^{12}$ Presence of an airway anomaly was based on International Pediatric and Congenital Cardiac Code definitions ${ }^{13}$ : major abnormality of the larynx-trachea-bronchus, congenital tracheal stenosis, laryngomalacia, tracheomalacia, bronchomalacia, or other major abnormality of the larynx-trachea-bronchus. Acquired diaphragm paralysis and vocal cord dysfunction also were evaluated as potential risk factors. The Society of Thoracic Surgeons-European Association for Cardiothoracic Surgery mortality categories were used to classify surgical complexity. ${ }^{14}$ The timing of renal replacement therapy relative to extubation failure could not be determined reliably, so renal replacement therapy was excluded from the risk factor analysis.

We defined extubation failure as reintubation less than 72 hours after the first planned extubation. Reintubations occurring after 72 hours were not considered extubation failures. Various criteria have been used to define extubation failure in pediatric cardiac surgical patients ${ }^{8,9,15-17}$; this analysis focused on the first 72 hours after extubation because this period seems to be most clinically relevant in the neonatal population and most closely reflects the consequences of the clinical team's decision to remove the patient from mechanical ventilation. We further assessed rates of in-hospital mortality, cardiac ICU duration, and hospital length of stay (LOS) in patients with and without extubation failure to contextualize our results with previous literature. , $5,7,8^{-}$

\section{Statistical Analysis}

Clinical characteristics and outcomes are presented as frequency (percentage) for categoric variables and median (interquartile range) for continuous variables. The rates of extubation failure were described as percentages. Bivariate comparisons were performed with chi-square, Fisher exact test, or Wilcoxon rank-sum test as appropriate. To identify clinical characteristics associated with extubation failure, repeatedmeasures analysis using generalized estimating equations (GEEs) with a logit function was used to account for correlation between outcomes of patients at the same center. Factors associated with extubation failure in unadjusted analysis $(P<.1)$ were subsequently included in the multivariable analysis to determine independent association. Although Society of Thoracic Surgeons-European Association for Cardio-Thoracic Surgery Congenital Heart Surgery Mortality Category did not reach this statistical threshold, these data were included in the multivariable analysis, grouped into categories 1 to 3 and 4 to 5 to minimize the degrees of freedom in the model and is consistent with prior approaches. ${ }^{18-20}$ Adjusted odds ratios and their $95 \%$ confidence intervals were reported.

Variability in the extubation failure rates across the 14 centers was assessed. Centers with less than 20 cases at the time of analysis ( 3 centers with a total of 33 observations) were excluded from this analysis because of the small sample size. After multivariable analysis of risk factors (and considering data quality and frequency distribution within the population), a second multivariable logistic regression model was developed to estimate the expected rate of extubation failure by center. This second model did not include factors possibly related to hospital quality (eg, complications). GEE was used to account for clustering, and $95 \%$ biased corrected confidence intervals were derived by a 1000 bootstrapping resampling method. The risk-adjusted extubation failure rate was calculated by dividing the center's observed rate by the expected rate calculated from the model and then multiplied by the overall observed extubation failure rate across all centers.

A secondary analysis was conducted to determine whether certain risk factors were differentially associated with early $(<24$ hours) versus late (24-72 hours) extubation failure. Factors from the primary analysis were included in the secondary analysis, and GEE was again used to control for clustering within center. A generalized logit model was created, and the multiple outcome groups were categorized as early extubation failure ( $<24$ hours), late extubation failure (24-72 hours), and none (no extubation failure within 72 hours). This analytic strategy was chosen on the basis of our clinical judgment that there is no ordinal relationship across the outcome groups and that the question of interest was whether the covariates were associated differently with early or late extubation failure. We explored a second model in which we separated the "no extubation failure" group into those patients who were never reintubated (reference group) and those who were reintubated after 72 hours (4 response categories for the dependent variable). This model yielded similar results, and, for simplicity, we present the associated relative risk ratios in the early and late extubation failure groups $(<24$ hours and $24-72$ hours vs no extubation failure). Analyses were performed using SAS Version 9.4 (SAS Institute Inc, Cary, NC) or STATA Version 14 (StataCorp LP, College Station, Tex).

\section{RESULTS}

\section{Patient Characteristics}

Among the 14 participating $\mathrm{PC}^{4}$ centers, 899 neonates were identified. Only 10 neonates were excluded from the analysis on the basis of exclusion criteria. Demographics and perioperative characteristics are summarized in Table 1. Most of these neonates had their index operation by 7 days of age. Prematurity $(14 \%)$, genetic syndromes $(21 \%)$, and major noncardiac anomalies $(18 \%)$ occurred commonly in the overall population. The most common noncardiac anomalies were renal system anomalies $(24$, $2.7 \%$ ), intestinal malrotation $(17,1.9 \%)$, and spinal malformations $(19,1.9 \%)$, with most other anomalies occurring only once or twice. Airway anomalies were present in $4 \%$ of study patients and are detailed in Table 2 . Many patients received preoperative mechanical ventilation $(40 \%)$ and had Society of Thoracic Surgeons-European Association for Cardio-Thoracic Surgery Congenital Heart Surgery category 4 or 5 operations $(60 \%)$. Postoperative open sternum $(29 \%)$ and inhaled nitric oxide $(21 \%)$ were prevalent. Other postoperative events or complications, including extracorporeal life support, cardiopulmonary resuscitation, vocal cord dysfunction, and diaphragm paralysis, were uncommon.

\section{Epidemiology of Postoperative Neonatal Extubation Failure}

Of the 899 neonates analyzed, $103(11 \%)$ failed extubation within 72 hours after their initial extubation attempt. There was considerable variability among centers, with unadjusted extubation failure rates from $5 \%$ to $22 \%$ (Figure 1). Case-mix adjusted rates accounting for Society of Thoracic Surgeons-European Association for Cardio-Thoracic Surgery Congenital Heart Surgery Category and airway anomaly did not affect an individual center's extubation failure rate and demonstrated similar variability $(6 \%-23 \%)$. Most extubation failures occurred early (within the first 24 hours; $61 \%$ ) versus later $(39 \%, 24-72$ hours) (Figure 2).

\section{Risk Factors Associated With Extubation Failure}

Table 1 compares the demographics and perioperative characteristics of patients with and without extubation 
TABLE 1. Demographics and perioperative characteristics for 72-hour extubation failure after neonatal congenital heart surgery

\begin{tabular}{|c|c|c|c|c|}
\hline & $\frac{\text { Total population }}{(\mathrm{n}=899)}$ & $\frac{\text { Extubation success }}{(\mathrm{n}=796)}$ & $\frac{\text { Extubation failure }}{(n=103)}$ & $P$ value \\
\hline \multicolumn{5}{|l|}{ Demographic characteristics } \\
\hline Age at admission, $\mathrm{d}$ & $0(0,2)$ & $0(0,2)$ & $0(0,2)$ & .99 \\
\hline Age at surgery, $d$ & $7(4,11)$ & $7(4,12)$ & $7(3,10)$ & .43 \\
\hline Weight at admission, $\mathrm{kg}$ & $3.2(2.7,3.5)$ & $3.2(2.7,3.5)$ & $3.2(2.7,3.5)$ & .82 \\
\hline Weight-for-age at admission, z-score & $-0.4(-1.4$ to 0.4$)$ & $-0.4(-1.4$ to 0.4$)$ & $-0.4(-1.5$ to 0.3$)$ & .91 \\
\hline Male gender & $523(58 \%)$ & $455(57 \%)$ & $68(66 \%)$ & .09 \\
\hline Prematurity (<37 wk) & $129(14 \%)$ & $112(14 \%)$ & $14(17 \%)$ & .55 \\
\hline Any genetic syndrome & $184(21 \%)$ & $163(21 \%)$ & $21(20 \%)$ & .99 \\
\hline DiGeorge & $35(4 \%)$ & $32(4 \%)$ & $3(3 \%)$ & .78 \\
\hline Trisomy 21 & $24(3 \%)$ & $21(3 \%)$ & $3(3 \%)$ & .75 \\
\hline Turner's & $10(1 \%)$ & $9(1 \%)$ & $1(1 \%)$ & .99 \\
\hline Other & $115(13 \%)$ & $101(13 \%)$ & $14(14 \%)$ & .76 \\
\hline Noncardiac structural anomalies & $162(18 \%)$ & $138(17 \%)$ & $24(23 \%)$ & .14 \\
\hline Both a noncardiac structural anomalies and a genetic syndrome & $80(9 \%)$ & $69(9 \%)$ & $11(11 \%)$ & .50 \\
\hline Airway anomaly & $36(4 \%)$ & $26(3 \%)$ & $10(10 \%)$ & .005 \\
\hline Preoperative mechanical ventilation & $363(40 \%)$ & $316(40 \%)$ & $47(46 \%)$ & .29 \\
\hline \multicolumn{5}{|l|}{ Operative characteristics } \\
\hline \multicolumn{5}{|c|}{ Society of Thoracic Surgeons-European Association for Cardio-Thoracic Surgery Congenital Heart Surgery mortality category } \\
\hline Category 1 & $58(7 \%)$ & $53(7 \%)$ & $5(5 \%)$ & .67 \\
\hline Category 2 & $130(15 \%)$ & $118(15 \%)$ & $12(12 \%)$ & .46 \\
\hline Category 3 & $172(19 \%)$ & $155(20 \%)$ & $17(17 \%)$ & .51 \\
\hline Category 4 & $375(42 \%)$ & $326(41 \%)$ & $49(48 \%)$ & .20 \\
\hline Category 5 & $156(17 \%)$ & $138(17 \%)$ & $18(18 \%)$ & .99 \\
\hline Cardiopulmonary bypass & $667(74 \%)$ & $585(74 \%)$ & $82(80 \%)$ & .19 \\
\hline Cardiopulmonary bypass time, min & $112(80,162)$ & $112(80,163)$ & $111(81,148)$ & .71 \\
\hline Deep hypothermic circulatory arrest & $343(51 \%)$ & $298(52 \%)$ & $45(55 \%)$ & .56 \\
\hline Delayed sternal closure & $258(29 \%)$ & $223(28 \%)$ & $35(34 \%)$ & .21 \\
\hline \multicolumn{5}{|l|}{ Pre-extubation events } \\
\hline Cardiopulmonary resuscitation & $33(4 \%)$ & $29(4 \%)$ & $4(4 \%)$ & .78 \\
\hline Extracorporeal life support & $52(6 \%)$ & $42(5 \%)$ & $10(10 \%)$ & .08 \\
\hline Necrotizing enterocolitis & $17(2 \%)$ & $13(2 \%)$ & $4(4 \%)$ & .12 \\
\hline Any infection & $31(3 \%)$ & $27(3 \%)$ & $4(4 \%)$ & .77 \\
\hline Stroke & $8(1 \%)$ & $8(1 \%)$ & 0 & .61 \\
\hline Seizures & $23(3 \%)$ & $22(3 \%)$ & $1(1 \%)$ & .50 \\
\hline Inhaled nitric oxide & $191(21 \%)$ & $160(20 \%)$ & $31(30 \%)$ & .03 \\
\hline Vocal cord dysfunction & $5(0.5 \%)$ & $4(0.5 \%)$ & $1(1 \%)$ & .46 \\
\hline Diaphragmatic paralysis & $4(0.4 \%)$ & $3(0.4 \%)$ & $1(1 \%)$ & .39 \\
\hline Weekend extubation & $188(21 \%)$ & $173(22 \%)$ & $15(15 \%)$ & .10 \\
\hline Any unplanned extubation & $5(0.6 \%)$ & $5(0.6 \%)$ & 0 & 1.00 \\
\hline Total mechanical ventilation, $\mathrm{h}$ & $70(26-144)$ & $69(25-141)$ & $95(43-170)$ & .03 \\
\hline
\end{tabular}

Median (25th, 75th percentiles) or number (percentage) are reported. $P$ value calculated with chi-square or Fisher exact test for categoric variables and Wilcoxon rank-sum test for continuous variables.

failure at 72 hours. The presence of an airway anomaly and the use of inhaled nitric oxide were associated with extubation failure in the bivariate analysis, but only airway anomaly remained associated with extubation failure on multivariable analysis (adjusted odds ratio, 3.1; 95\% confidence interval, 1.4-6.7; $P=.01$ ). Details of the final multivariable model are presented in Table 3. The secondary analysis, which compared risk factors for early ( $<24$ hours) and late (24-72 hours) extubation failures, is presented in Table 4 and is generally consistent with the primary model. The presence of an airway anomaly was associated with increased relative risk during both time periods, whereas the use of inhaled nitric oxide was associated with late extubation failure. Male gender was associated with an increased relative risk of early extubation failure only. Surgical complexity, cardiopulmonary bypass, the use of open sternum, extracorporeal life support, and the duration of mechanical ventilation before first planned extubation were not associated with increased risk of extubation failure in either model. 
TABLE 2. Breakdown of airway anomalies for the entire neonatal cohort $(n=899)$

\begin{tabular}{ll}
\hline Airway anomalies $(\mathrm{n}=36)$ & \\
Bronchomalacia & $14(1.6 \%)$ \\
Tracheomalacia & $14(1.6 \%)$ \\
Laryngomalacia & $11(1.2 \%)$ \\
Other & $10(1.1 \%)$ \\
\hline Unique patients can have multiple anomalies. &
\end{tabular}

\section{Impact of Extubation Failure on Patient Outcomes}

As expected, patients who experienced extubation failure demonstrated worse unadjusted acute outcomes (Table 5) compared with those who did not. Mortality was increased 3.4-fold, hospital LOS was increased 1.4-fold, and duration of cardiac ICU stay was increased 2.1-fold in patients with extubation failure compared with those without.

\section{DISCUSSION}

This analysis used a rigorous multi-institutional cardiac critical care registry to describe the epidemiology of neonatal postoperative extubation failure. Extubation failure occurred commonly in neonates after congenital heart surgery; the frequency was nearly twice that reported in a prior study from the $\mathrm{PC}^{4}$ registry examining extubation failure in a broader population of mechanically ventilated children in cardiac ICUs. ${ }^{4}$ This increased risk likely is due to a combination of factors, including the physiologic cardiopulmonary limitations of neonates, more complex surgical procedures with greater postoperative illness severity, and challenges within assessment of extubation readiness in neonates. ${ }^{4,5}$

This analysis is the first to highlight the considerable variation in neonatal extubation failure rates across centers.

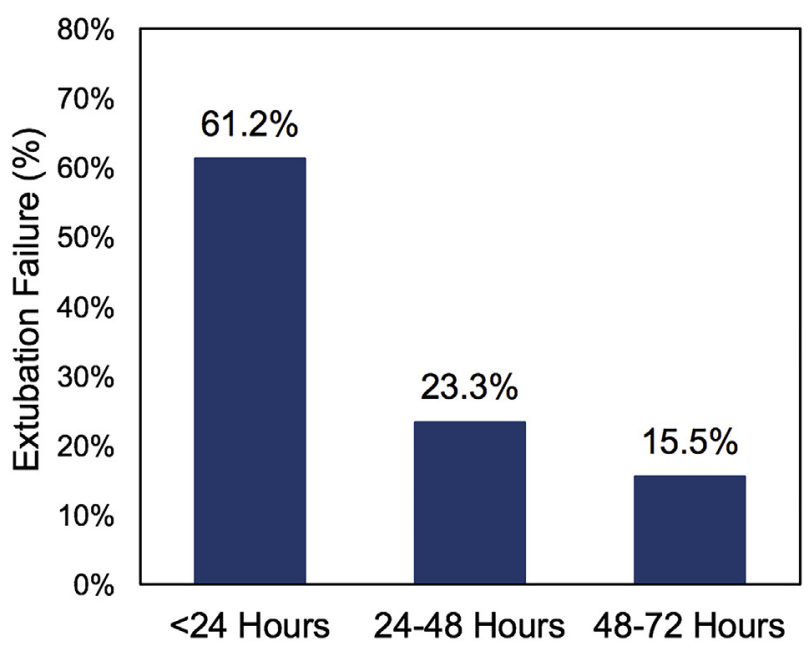

FIGURE 2. Distribution of time to extubation failure less than 72 hours for neonates after congenital heart surgery. The majority of extubation failures occurred early, within 24 hours of extubation failure.

The variability is consistent even after controlling for procedure complexity and airway anomalies. In the only single-center study focused on a heterogeneous population of neonates who underwent cardiac surgery, Laudato and colleagues $^{7}$ reported an extubation failure rate of $17.5 \%$, which also was within the range observed in our study. Although an acceptable rate of extubation failure is unknown, these data identify the need for collaboration among institutions to glean insight into possible explanations for this variation. Multicenter collaboratives such as $\mathrm{PC}^{4}$ provide the infrastructure to identify high-performing centers and generate opportunities to share best practices. For example, this study suggests that there are at least 2 centers with greater than average neonatal

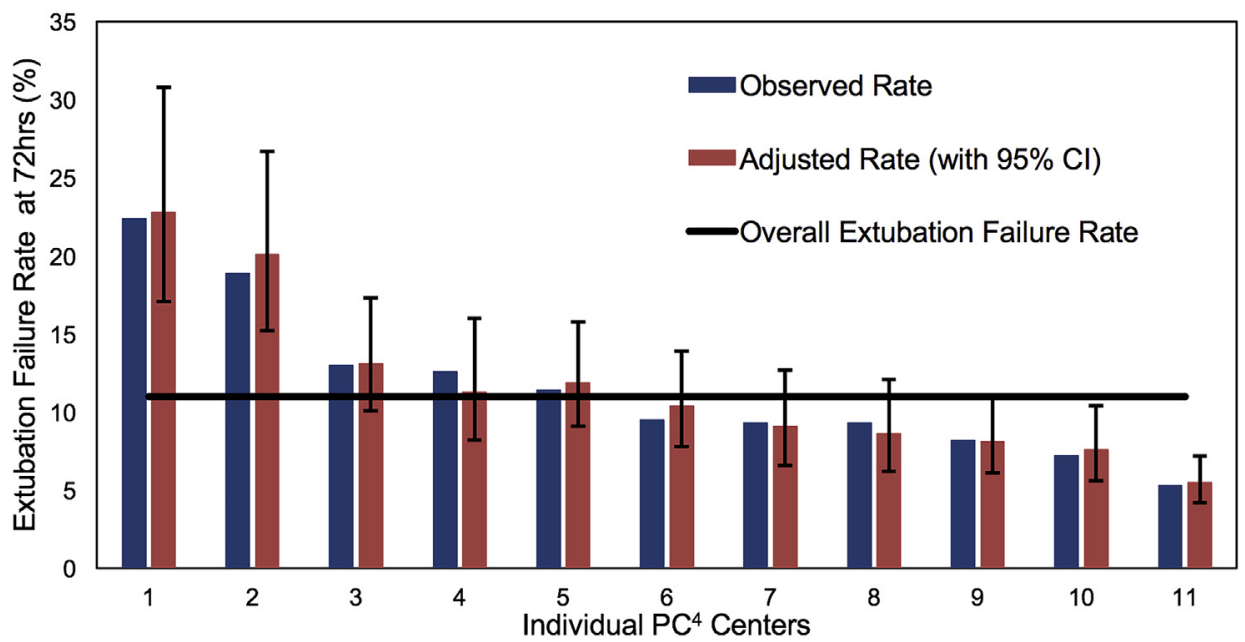

FIGURE 1. Observed and adjusted rates of extubation failure for neonates after congenital heart surgery by $\mathrm{PC}^{4}$ center. Observed rates of extubation failure are presented for the 11 centers with more than 20 cases ( 3 centers excluded). Adjusted rates (with $95 \%$ confidence intervals) of extubation failure are presented after controlling for procedure severity and airway anomaly. The overall extubation failure rate for this cohort is presented. CI, Confidence interval; $P C^{4}$, Pediatric Cardiac Critical Care Consortium. 
TABLE 3. Multivariable analysis of risk factors associated with 72-hour extubation failure after neonatal congenital heart surgery

\begin{tabular}{|c|c|c|c|}
\hline Characteristics & OR & 95\% CI & $P$ value \\
\hline Male gender & 1.44 & $(0.93-2.25)$ & .10 \\
\hline Airway anomaly & 3.06 & $(1.40-6.72)$ & .01 \\
\hline \multicolumn{4}{|c|}{ Society of Thoracic Surgeons-European Association for Cardio-Thoracic Surgery Congenital Heart Surgery mortality category } \\
\hline Categories $1-3$ & ref & & \\
\hline Categories 4 or 5 & 1.31 & $(0.83-2.09)$ & .25 \\
\hline Pre-extubation extracorporeal life support & 1.36 & $(0.60-3.08)$ & .47 \\
\hline Use of inhaled nitric oxide & 1.52 & $(0.92-2.51)$ & .10 \\
\hline \multicolumn{4}{|c|}{ Total mechanical ventilation (stratified into quartiles) } \\
\hline$\leq 25 \mathrm{~h}$ & ref & & \\
\hline $26-70 \mathrm{~h}$ & 1.05 & $(0.55-2.00)$ & .88 \\
\hline $70-144 \mathrm{~h}$ & 0.93 & $(0.47-1.83)$ & .84 \\
\hline$>144 \mathrm{~h}$ & 1.15 & $(0.57-2.31)$ & .69 \\
\hline
\end{tabular}

Generalized estimating equations used to account for effects of clustering of patients at the same center. $O R$, Odds ratio; $C I$, confidence interval.

extubation failure rates. Further investigation into specific center practices and collaborative learning with centers that have lower rates of extubation failure could stimulate practice changes. Specifically, this process of comparing outcomes between centers and sharing clinical practices could allow the field to maximize the benefits of early extubation while minimizing the risks of extubation failure. $\mathrm{PC}^{4}$ encourages this type of collaborative processes through the fully transparent disclosure of clinical outcomes among participants.

This study aimed to identify potential risk factors related to neonatal postoperative extubation failure, but only airway anomaly was consistently found to be independently associated with its occurrence. The analysis considered many factors (eg, prematurity, genetic syndromes, diaphragmatic paralysis, cardiopulmonary bypass, procedure complexity, extracorporeal life support, delayed sternal closure, postoperative infections, and duration of mechanical ventilation) that have been reported as risk factors in previous analyses. ${ }^{4,5,7-9,21,22}$ None of these variables were independently associated with extubation failure in this large multicenter dataset of neonates who underwent cardiac surgery. Some of the aforementioned risk factors, especially those identified in single-center studies, may be unique to those institutions. Further, extubation failure, especially in neonates, can result from several causes (eg, cardiac insufficiency, upper airway obstruction, atelectasis, pleural effusion, aspiration), which can complicate attempts at identifying more universal risk factors in large populations. Future studies examining subpopulations of neonates categorized by suspected cause of extubation failure (data not available within most clinical registries) could prove more fruitful in identifying risk factors. However, this dataset did allow for analysis of different risk factors depending on the timing of extubation failure. Although airway anomalies were consistently associated with extubation failure both early ( $<24$ hours) and late ( $24-72$ hours), nitric oxide use was found to be associated with later extubation failure. Whether this later finding reflects true physiologic causes or different practices in the extubation of high-risk neonates

TABLE 4. Secondary analysis of risk factors associated with early ( $<24$ hours) and late (24-72 hours) extubation failure after neonatal congenital heart surgery

\begin{tabular}{|c|c|c|}
\hline & \multicolumn{2}{|c|}{ Relative risk ratios $(95 \% \mathrm{CI})$} \\
\hline & Early $(<\mathbf{2 4}$ h) & Late (24-72 h) \\
\hline Airway anomaly & $4.65(2.59-8.36)^{*}$ & $3.12(1.17-8.32)^{*}$ \\
\hline Male gender & $1.94(1.18-3.18)^{*}$ & $0.87(0.52-1.44)$ \\
\hline \multicolumn{3}{|c|}{ Society of Thoracic Surgeons-European Association for Cardio-Thoracic Surgery Congenital Heart Surgery mortality category } \\
\hline Categories $1-3$ & ref & ref \\
\hline Categories $4-5$ & $1.47(0.72-3.00)$ & $1.19(0.69-2.04)$ \\
\hline Pre-extubation extracorporeal life support & $1.77(0.58-5.46)$ & $1.76(0.46-6.71)$ \\
\hline Use of inhaled nitric oxide & $1.40(0.81-2.40)$ & $2.00(1.06-3.76)^{*}$ \\
\hline \multicolumn{3}{|c|}{ Total mechanical ventilation (stratified into quartiles) } \\
\hline$\leq 25 \mathrm{~h}$ & ref & ref \\
\hline $26-70 \mathrm{~h}$ & $1.29(0.68-2.47)$ & $0.85(0.41-1.80)$ \\
\hline $70-144 \mathrm{~h}$ & $1.06(0.67-1.68)$ & $1.08(0.33-3.54)$ \\
\hline$>144 \mathrm{~h}$ & $1.42(0.85-2.36)$ & $1.38(0.51-3.77)$ \\
\hline
\end{tabular}


TABLE 5. Outcomes associated with 72-hour extubation failure after neonatal congenital heart surgery

\begin{tabular}{|c|c|c|c|c|}
\hline & Total population $(n=899)$ & Extubation success $(n=796)$ & Extubation failure $(n=103)$ & $P$ value \\
\hline Cardiac ICU duration, $\mathrm{d}$ & $8(5-15)$ & $8(4-14)$ & $16(9-31)$ & .001 \\
\hline Hospital LOS, d & $24(15-39)$ & $23(14-37)$ & $33(21-54)$ & .001 \\
\hline Hospital mortality & $26(3 \%)$ & $18(2 \%)$ & $8(8 \%)$ & .002 \\
\hline
\end{tabular}

Median (25th, 75th percentiles) or number (percentage) reported. $P$ value calculated with chi-square or Fisher exact test for categoric variables and Wilcoxon rank-sum test for continuous variables. ICU, Intensive care unit; $L O S$, length of stay.

with suspected pulmonary hypertension remains unknown and warrants further study.

As suggested by previous single-center studies, ${ }^{7,8}$ our cohort of neonates experiencing extubation failure also demonstrated worse overall clinical outcomes. Some of this association likely is explained by factors other than the extubation failure, because it is likely that patients who fail extubation have other comorbidities and additional complications that prolong their LOS and increase their mortality risk. We did not assess the degree to which extubation failure affects these outcomes in this analysis because to do so would require more specific case mix adjustment models for neonatal surgical mortality and LOS that include postoperative events and markers of physiologic derangement. These models currently do not exist in the literature. However, our experience in caring for these patients and that of others suggests that extubation failure directly affects these outcomes and places patients at risk for major morbidity, such as airway injury, cardiac arrest, and the welldescribed sequelae of prolonged intensive care. ${ }^{23-25}$ Additional work to understand the isolated contribution of extubation failure to other clinical outcomes is necessary to understand how practices should balance aggressiveness to wean from mechanical ventilation with possible consequences of extubation failure. Because few patient- and operative-related risk factors were identified, future work likely will focus on identifying center-related factors that affect extubation failure rates. The $\mathrm{PC}^{4}$ organization is uniquely situated to facilitate that work. Congenital heart surgical outcome assessment likely is to follow adult heart surgery ${ }^{26-28}$ and shift from mortality to composite measures of overall clinical outcomes, including mortality, LOS, and complications. ${ }^{29}$ This shift will encourage enhanced collaboration among surgeons, anesthesia, intensive care, and cardiology to optimize the postoperative care.

\section{Study Limitations}

This analysis has many of the common limitations inherent to the use of observational and multi-institutional registry data. Registry data cannot contain all of the potential variables that might explain a specific outcome (eg, assessment of residual lesions after surgery). Noninvasive ventilation practices were not assessed because the data structure of the registry does not allow analysis of the questions of interest, most notably whether these therapies are used prophylactically or as rescue. Registry data also cannot account for any subjective aspects of clinicians' decisions to reintubate, which likely have interand intra-institutional variation. No attempt was made to identify the specific reason for extubation failure because that variable is not likely to be accurately captured from chart abstraction. The definition of extubation failure by 72 hours chosen for this study likely excluded some important extubation failure events that occurred later, but it also eliminated confusion around reintubations that are unrelated to the first planned extubation attempt. Further work could clarify extubation failures occurring after 72 hours, but additional data around the reason for intubation would be needed. The secondary analysis evaluating early versus late extubation failure included some groups with small numbers. As such, the model estimates are less stable, and the reliability of the findings must be confirmed in a repeat analysis with greater sample size. Last, this study reflects the practice at cardiac ICUs in the $\mathrm{PC}^{4}$, and as such the results may not be generalizable to all cardiac ICU settings.

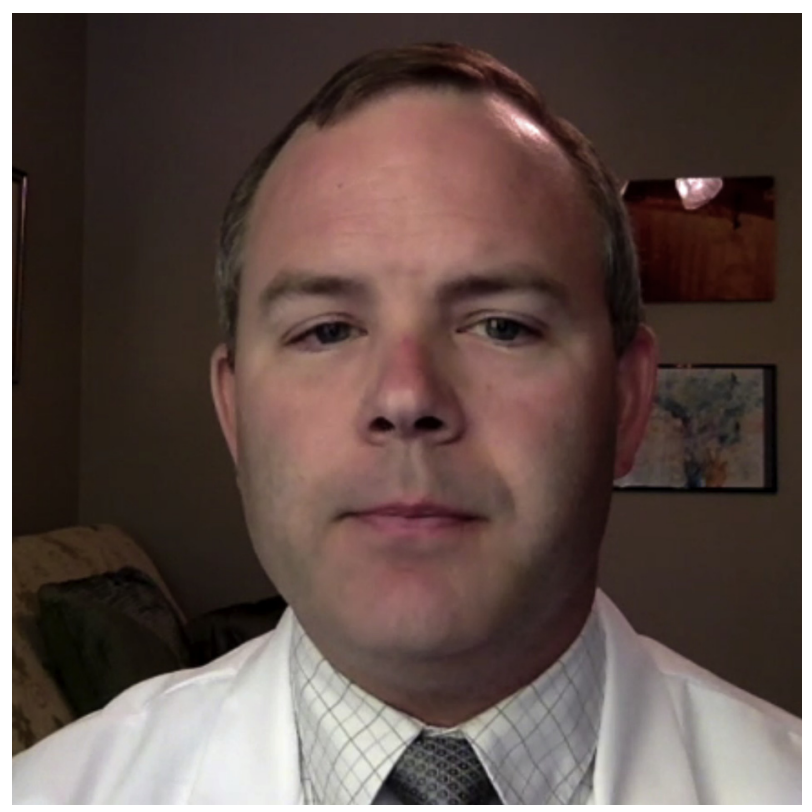

VIDEO 1. Dr Benneyworth discusses the dominant findings of the study. Video available at: http://www.jtcvsonline.org/article/S0022-5223(17) 30153-8/addons. 


\section{CONCLUSIONS}

Extubation failure after neonatal congenital heart surgery occurs in approximately $11 \%$ of patients in contemporary cardiac ICUs, with wide variability across centers (5\%-22\%). Despite undergoing procedures that require significant cardiopulmonary support and postoperative care, airway anomalies are the predominant risk factor for extubation failure in the neonatal population. Future work should focus on minimizing extubation failure while limiting exposure to mechanical ventilation and on identifying differences in practices among cardiac ICUs that affect variability in these outcome measures (Video 1).

\section{Conflict of Interest Statement}

Authors have nothing to disclose with regard to commercial support.

The authors thank the data-collection teams at all of the participating centers and the generous donors to the University of Michigan Congenital Heart Center and CHAMPS for Mott for their support of $\mathrm{PC}^{4}$.

\section{References}

1. Harris KC, Holowachuk S, Pitfield S, Sanatani S, Froese N, Potts JE, et al. Should early extubation be the goal for children after congenital cardiac surgery? J Thorac Cardiovasc Surg. 2014;148:2642-7.

2. Polito A, Patorno E, Costello JM, Salvin JW, Emami SM, Rajagopal S, et al. Perioperative factors associated with prolonged mechanical ventilation after complex congenital heart surgery. Pediatr Crit Care Med. 2011;12:e122-6.

3. Tabbutt S. Can multicenter registries determine the optimal timing of extubation after congenital heart surgery? J Thorac Cardiovasc Surg. 2016; 151:458-9.

4. Gaies M, Tabbutt S, Schwartz SM, Bird GL, Alten JA, Shekerdemian LS, et al. Clinical epidemiology of extubation failure in the pediatric cardiac ICU. Pediatr Crit Care Med. 2015;16:837-45.

5. Gupta P, Rettiganti M, Gossett JM, Yeh JC, Jefferies HE, Rice TB, et al. Risk factors for mechanical ventilation and reintubation after pediatric heart surgery. $J$ Thorac Cardiovasc Surg. 2016;151:451-8.e3.

6. Mahle WT, Nicolson SC, Hollenbeck-Pringle D, Gaies MG, Witte MK, Lee EK, et al. Utilizing a collaborative learning model to promote early extubation following infant heart surgery. Pediatr Crit Care Med. 2016;17:939-47.

7. Laudato N, Gupta P, Walters HL, Dellus RE, Mastropietro CW. Risk factors for extubation failure following neonatal cardiac surgery. Pediatr Crit Care Med. 2015; 16:859-67.

8. Gupta P, McDonald R, Gossett JM, Butt W, Shinkawa T, Imamura M, et al. A single-center experience of extubation failure in infants undergoing the Norwood operation. Ann Thorac Surg. 2012;94:1262-8.

9. Miller JW, Vu D, Chai PJ, Kreutzer J, Hossain M, Jacobs JP, et al. Patient and procedural characteristics for successful and failed immediate tracheal extubation in the operating room following cardiac surgery in infancy. Paediatr Anaesth. 2014;24:830-9.

10. Gaies M, Cooper DS, Tabbutt S, Schwartz SM, Ghanayem N, Chanai NK, et al. Collaborative quality improvement in the cardiac intensive care unit: development of the Paediatric Cardiac Critical Care Consortium (PC4). Cardiol Young. 2015;25:951-7.

11. Gaies M, Donohue JE, Willis GM, Kennedy AT, Butcher J, Scheurer MA, et al. Data integrity of the Pediatric Cardiac Critical Care Consortium (PC4) clinical registry. Cardiol Young. 2016;26:1090-6.
12. Growth Chart, Data Tables [Internet]. Atlanta, GA: Centers for Disease Control and Prevention. Available at: http://www.cdc.gov/growthcharts/data_tables.htm. Accessed August 2015.

13. Jacobs JP, Jacobs ML, Mavroudis C, Backer CL, Lacour-Gayet FG, Tchervenkov CI, et al. Nomenclature and databases for the surgical treatment of congenital cardiac disease-an updated primer and an analysis of opportunities for improvement. Cardiol Young. 2008;18(Suppl 2):38-62.

14. Jacobs JP, Jacobs ML, Maruszewski B, Lacour-Gayet FG, Tchervenkov CI, Tobata Z, et al. Initial application in the EACTS and STS Congenital Heart Surgery Databases of an empirically derived methodology of complexity adjustment to evaluate surgical case mix and results. Eur J Cardiothorac Surg. 2012;42: 775-9.

15. Manrique AM, Feingold B, Di Filippo S, Orr RA, Kuch BA, Munoz R. Extubation after cardiothoracic surgery in neonates, children, and young adults: one year of institutional experience. Pediatr Crit Care Med. 2007;8: $552-5$.

16. Edmunds S, Weiss I, Harrison R. Extubation failure in a large pediatric ICU population. Chest. 2001;119:897-900.

17. Dodgen AL, Dodgen AC, Swearingen CJ, Gossett JM, Dasgupta R, Butt W, et al. Characteristics and hemodynamic effects of extubation failure in children undergoing complete repair for tetralogy of Fallot. Pediatr Cardiol. 2013;34: 1455-62.

18. DiBardino DJ, Pasquali SK, Hirsch JC, Benjamin DK, Kleeman KC, Salazar JD, et al. Effect of sex and race on outcome in patients undergoing congenital heart surgery: an analysis of the society of thoracic surgeons congenital heart surgery database. Ann Thorac Surg. 2012;94:2054-9.

19. Alsoufi B, Manlhiot C, Mahle WT, Kogon B, Border WL, Cuadrado A, et al. Low-weight infants are at increased mortality risk after palliative or corrective cardiac surgery. J Thorac Cardiovasc Surg. 2014;148:2508-14.

20. Alsoufi B, Gillespie S, Mahle WT, Deshpande S, Kogon B, Maher K, et al. the effect of noncardiac and genetic abnormalities on outcomes following neonatal congenital heart surgery. Semin Thorac Cardiovasc Surg. 2016;28: $105-14$.

21. Green J, Walters HL III, Delius RE, Sarnaik A, Mastropietro CW. Prevalence and risk factors for upper airway obstruction after pediatric cardiac surgery. J Pediatr. 2015;166:332-7.

22. Averin K, Uzark K, Beekman RH III, Willging JP, Pratt J, Manning PB. Postoperative assessment of laryngopharyngeal dysfunction in neonates after Norwood operation. Ann Thorac Surg. 2012;94:1257-61.

23. Baisch SD, Wheeler WB, Kurachek SC, Cornfield DN. Extubation failure in pediatric intensive care incidence and outcomes. Pediatr Crit Care Med. 2005; 6:312-8.

24. Harkel AD, van der Vorst MM, Hazekamp MG, Ottenkamp J. High mortality rate after extubation failure after pediatric cardiac surgery. Pediatr Cardiol. 2005;26: 756-61.

25. Pasquali SK, He X, Jacobs ML, Shah SS, Peterson ED, Gaies MG, et al. Excess costs associated with complications and prolonged length of stay after congenital heart surgery. Ann Thorac Surg. 2014;98:1660-6.

26. Shahian DM, He X, Jacobs JP, Rankin JS, Welke KF, Edwards FH, et al. The STS AVR + CABG composite score: a report of the STS Quality Measurement Task Force. Ann Thorac Surg. 2014;97:1604-9.

27. Shahian DM, Edwards FH, Ferraris VA, Haan CK, Rich JB, Normand SL, et al. Quality measurement in adult cardiac surgery: part 1-conceptual framework and measure selection. Ann Thorac Surg. 2007;83:S3-12.

28. Shahian DM, O'Brien SM, Normand S-LT, Peterson ED, Edwards FH. Association of hospital coronary artery bypass volume with processes of care, mortality, morbidity, and the Society of Thoracic Surgeons composite quality score. J Thorac Cardiovasc Surg. 2010;139:273-82.

29. Pasquali SK, Wallace AS, Gaynor JW, Jacobs ML, O’Brien SM, Hill KD, et al. Congenital heart surgery case mix across North American centers and impact on performance assessment. Ann Thorac Surg. 2016; 102:1580-7.

Key Words: congenital heart disease, postoperative care, extubation failure, mechanical ventilation 